\title{
Disparity in Neurotransmitter Release Probability among Competing Inputs during Neuromuscular Synapse Elimination
}

\author{
Diane M. Kopp, David J. Perkel, and Rita J. Balice-Gordon \\ Department of Neuroscience, University of Pennsylvania School of Medicine, Philadelphia, Pennsylvania 19104-6074
}

\begin{abstract}
Competition among the several motor axons transiently innervating neonatal muscle fibers results in an increasing disparity in the quantal content and synaptic territory of each competitor, culminating in the permanent loss of all but one axon from neuromuscular junctions. We asked whether differences in the probability of neurotransmitter release also contribute to the increasing disparity in quantal content among competing inputs, and when in the process of competition changes in release probability become apparent. To address these questions, intracellular recordings were made from dually innervated neonatal mouse soleus muscle fibers, and quantal content and paired-pulse facilitation were evaluated for each input. At short interpulse intervals, paired-pulse facilitation was significantly higher for the weaker input with the smaller quantal content than the stronger
\end{abstract}

input with the larger quantal content. Because neurotransmitter release probability across all release sites is inversely related to the extent of facilitation observed after paired-pulse stimulation, this result suggests that release probability is lower for weak compared with strong inputs innervating the same junction. A disparity in the probability of neurotransmitter release thus contributes to the disparity in quantal content that occurs during synaptic competition. Together, this work suggests that an input incapable of sustaining a high release probability may be at a competitive disadvantage for synaptic maintenance.

Key words: synapse elimination; nerve terminal; quantal content; paired-pulse facilitation; motor neuron; synaptic transmission
Experience-dependent editing shapes synaptic connections throughout the developing nervous system, but the underlying mechanisms are poorly understood. At developing neuromuscular junctions transiently innervated by multiple motor axons, changes in the structure and strength of the synapses of each input occur in parallel. Previous work has shown that, as multiple innervation of muscle fibers is established, each input has relatively equal presynaptic terminal area (Balice-Gordon et al., 1993; Gan and Lichtman, 1998), occupies relatively equal areas of postsynaptic acetylcholine receptor (AChR)-rich membrane (Balice-Gordon and Lichtman, 1993; Gan and Lichtman, 1998), and has relatively equal synaptic strength as measured by quantal content (Colman et al., 1997), the number of neurotransmitter quanta released per stimulus. Thus, early in development, there appears to be a relative balance of power among competing inputs, only one of which will be maintained at each adult neuromuscular junction.

As competition begins, a progressive strengthening of some inputs and weakening of others is evident functionally as well as structurally within individual junctions. Quantal content becomes increasingly disparate among competing inputs (Colman et al., 1997), and the density of AChRs beneath some inputs is sharply reduced (Balice-Gordon and Lichtman, 1993), leading to a reduction in their quantal efficacy. The progressive loss of presynaptic terminals (Balice-Gordon and Lichtman, 1993; Gan and Lichtman, 1998) decreases the effective area for neurotransmitter release by weakened inputs. Cycles of functional weakening and structural loss continue until all of the sites innervated by weakened inputs are eliminated, and the losing axons permanently withdraw from the junction.

Although a reduction in the postsynaptic AChR density and

Received June 19, 2000; revised Aug. 21, 2000; accepted Sept. 7, 2000

This work was supported by National Institutes of Health Grant NS38517 (to R. B.-G.) and National Institutes of Health National Research Service Award NS10624 (to D. M. K.). We thank Dr. T. Parsons for advice and comments on earlier versions of this manuscript, Dr. P. Nealen for help with statistical analyses, and Drs. M. Gonzalez, Q. Chang, and K. Personius for helpful discussions.

Correspondence should be addressed to Rita Balice-Gordon, Department of Neuroscience, University of Pennsylvania School of Medicine, 215 Stemmler Hall, Philadelphia, PA 19104-6074. E-mail: rbaliceg@mail.med.upenn.edu.

Copyright $\odot 2000$ Society for Neuroscience $0270-6474 / 00 / 208771-09 \$ 15.00 / 0$ presynaptic terminal area contribute to the weakening of inputs, neurotransmitter release probability could also affect synaptic strength. To address whether differences in the probability of neurotransmitter release across all release sites contribute to the increasing disparity in quantal content among competing inputs, intracellular recordings were made from dually innervated neonatal mouse soleus muscle fibers, and quantal content and pairedpulse facilitation were evaluated for each input. Although measuring release probability directly is impossible in this preparation, even with optical approaches (Betz and Bewick, 1992; Ribchester et al., 1994), an indirect measure of release probability can be obtained from the extent of facilitation observed after paired-pulse stimulation. Neurotransmitter release probability is inversely related to the extent of facilitation observed after paired-pulse stimulation (Katz and Miledi, 1968; Mallart and Martin, 1968; Creager et al., 1980; Manabe et al., 1993; Dobrunz and Stevens, 1997). Analysis of quantal content and synaptic facilitation showed that neurotransmitter release probability differed dramatically among competing inputs. These results suggest that inputs with low neurotransmitter release probability may be at a competitive disadvantage for synaptic maintenance.

Parts of this work have been published previously in abstract form (Kopp and Balice-Gordon, 1999).

\section{MATERIALS AND METHODS}

Immunohistochemical analysis of multiply innervated neuromuscular junctions. The soleus muscle was chosen for these experiments because of the following: junctions are located in a single band in the middle of the muscle belly; the muscle and its innervation can be easily dissected back to ventral root filaments; axons are located in two or three ventral roots that can be easily separated for stimulation; and this muscle has been widely used for structural and functional studies of synapse elimination. Whole mounts of postnatal day 1 (P1) to P14 soleus muscles from CD1 mice (Harlan Sprague Dawley, Indianapolis, IN) were immunostained for motor axons, nerve terminals, and AChRs as described previously (Gonzalez et al., 1999), and the number of axons innervating junctions was evaluated by confocal microscopy (Leica TCS 4D system; Heidelberg, Germany) for at least 25 junctions from each of four muscles examined at each age.

Electrophysiological analyses of synaptic transmission. P7-P9 mice were anesthetized by intraperitoneal injection of $0.05 \mathrm{cc}$ of a mixture of 17.4 $\mathrm{mg} / \mathrm{ml} \mathrm{ketamine}$ and $2.6 \mathrm{mg} / \mathrm{ml}$ xylazine (Phoenix Pharmaceuticals, St. Joseph, MO). The soleus muscle and its innervation to the ventral roots were dissected under oxygenated $\left(95 \% \mathrm{O}_{2}, 5 \% \mathrm{CO}_{2}\right)$ Rees' Ringer's 
solution (Rees, 1978). The muscle was pinned in a Sylgard-lined Petri dish and superfused with oxygenated Ringer's, and ventral root fibers from L3L5 were carefully split and divided among two or three suction electrodes and stimulated with square pulses $(0.2 \mathrm{mV}$ to $2.0 \mathrm{~V}, 0.2 \mathrm{msec}$ duration). By adjusting the stimulus voltage to each suction electrode and visually monitoring muscle contractions, all ventral root bundles that contained soleus motor axons were identified.

Intracellular recording from skeletal muscle fibers was performed using glass microelectrodes filled with $3 \mathrm{M} \mathrm{KCl}(50-70 \mathrm{M} \Omega$ resistance). Contractions were prevented by adjusting the $\mathrm{Ca}^{2+} / \mathrm{Mg}^{2+}$ ratio of the Ringer's solution, and recordings were made under one of three conditions: low $\mathrm{Ca}^{2+}\left(1 \mathrm{mM} \mathrm{Ca}^{2+}, 8-10 \mathrm{mM} \mathrm{Mg}^{2+}\right)$, normal Ca ${ }^{2+}\left(2 \mathrm{mM} \mathrm{Ca}^{2+}, 13-15 \mathrm{~mm}\right.$ $\left.\mathrm{Mg}^{2+}\right)$, or high $\mathrm{Ca}^{2+}\left(4 \mathrm{mM} \mathrm{Ca}^{2+}, 24-27 \mathrm{~mm} \mathrm{Mg}{ }^{2+}\right)$. Magnesium concentration was adjusted using $\mathrm{MgSO}_{4}$. The exact $\mathrm{Mg}^{2+}$ required to block muscle contractions and to allow stable intracellular recordings varied somewhat from muscle to muscle, even in muscles from pups of the same age and in muscles from pups from the same litter. The minimal $\mathrm{Mg}^{2+}$ concentration that abolished contractions was used. Measurements of paired-pulse facilitation $(F)$ and quantal content $(m)$ of weak and strong inputs to the same junction were different regardless of $\mathrm{Mg}^{2+}$ concentration.

Muscle membrane potentials were amplified using an Axoprobe 1A amplifier (Axon Instruments, Foster City, CA), low-pass filtered at $1 \mathrm{kHz}$, and digitized at $10 \mathrm{kHz}$ using an analog-to-digital converter (DigiData; Axon Instruments) and interactive software (Axoscope; Axon Instruments).

By recording from a muscle fiber while independently altering the stimulation voltage to each ventral root bundle, the number of inputs to each fiber was counted and recorded. In initial experiments to count the number of inputs to junctions and choose the appropriate age range of animals for future studies, a total of 50 junctions was sampled from at least three P7, P8, and P9 muscles. Independent stimulation of each input resulted in an endplate potential (epp) that had a single amplitude component as well as constant rise time and duration. Muscle fibers that were innervated by only two axons, one from each of two different suction electrodes, were selected for further study. Stimulus intensity was set at 1.5 times threshold for eliciting an epp, stimulus frequency was $1 \mathrm{~Hz}$, and these generally remained constant for the duration of the experiment. Preparations that contained denervated muscle fibers, indicative of possible damage to axons during the dissection, were not studied further.

All experiments were performed at room temperature. The resting membrane potential was continuously monitored, and only fibers with resting potentials more hyperpolarized than $-55 \mathrm{mV}$, and in which the resting potential did not change by $>5 \mathrm{mV}$ during the course of the experiment, were studied further. In contrast to recordings from adult muscle fibers in which resting potentials of -70 to $-75 \mathrm{mV}$ were commonly obtained, it was difficult to obtain stable recordings for the length of time required from neonatal fibers. We found that $-55 \mathrm{mV}$ was the minimum resting potential that allowed us a sufficient signal-to-noise ratio to detect failures. A minimum of three junctions per muscle, from each of three animals, were examined at each age and experimental condition.

Quantal content was determined from 300-1000 stimuli (mean of 862) using the method of failures (Del Castillo and Katz, 1954). Quantal content $(m)$ was calculated as $\log _{\mathrm{e}}$ (\# of nerve impulses)/(\# failed responses). Mean epp amplitude was determined by averaging all events, including failures, and then measuring the amplitude of the averaged response from baseline to peak.

To determine the amount of paired-pulse facilitation $(F)$ (Mallart and Martin, 1968), two stimuli (0.2 msec duration) were given to one input at an interpulse interval (i.p.i.) of $10 \mathrm{msec}$. Five hundred to 1000 epps were collected at a rate of $1 \mathrm{~Hz}$. After 3-5 min rest, this was repeated at $1 \mathrm{sec}$ i.p.i., and data were collected at $0.2 \mathrm{~Hz}$. This paradigm was then repeated for the other input. These interpulse intervals were selected for comparison after a preliminary series of experiments in which $F$ was evaluated at 10, 20, 50, and $100 \mathrm{msec}$ and $1 \mathrm{sec}$ i.p.i. (see below). At $10 \mathrm{msec}$ i.p.i., $F$ was calculated by averaging all of the paired responses and then dividing the amplitude of the second averaged response (measured from its peak to the falling phase of the first response) by the amplitude of the first averaged response (measured from baseline to peak). At $1 \mathrm{sec}$ i.p.i., the amplitudes of both responses were measured from the baseline to the peak, and $F$ was calculated as described above. For some cells, $F$ was also determined by dividing the quantal content of the second response by the quantal content of the first response. In all cases, $F$ was similar when calculated by either method.

In some experiments, continuous recordings and evaluation of $F$ were made from the same muscle fiber while altering the $\mathrm{Ca}^{2+} / \mathrm{Mg}^{2+}$ composition of the Ringer's solution. The same fibers were recorded in at least two solutions. In these experiments, each Ringer's solution was allowed to perfuse over the muscle for at least $10 \mathrm{~min}$ before stimulation, a time sufficient to ensure both complete exchange of the solution and stable recording conditions.

In one set of experiments, intracellular recordings from skeletal muscle fibers were obtained in $4 \mathrm{mM} \mathrm{Ca}^{2+} / 1 \mathrm{mM} \mathrm{Mg}^{2+}$ in the presence of $7-10 \mu \mathrm{M}$ curare (Sigma, St. Louis, MO). In these experiments, $4 \mathrm{mM} \mathrm{Ca}^{2+}$ allowed stable recordings to be made over relatively long times from neonatal muscle fibers. Facilitation was examined at 10, 20, 50, and $100 \mathrm{msec}$ and 1 sec i.p.i.

Statistical analyses were done using Sigma Plot 4.0, Sigma Stat 2.03
(SPSS Inc., Chicago, IL) and Prism (GraphPad Software, San Diego, CA). Data are presented as mean $\pm \operatorname{SEM}(n=$ number of junctions).

\section{RESULTS}

\section{Differences in quantal content among competing inputs} at dually innervated soleus neuromuscular junctions

Intracellular recording of epps from P7-P9 soleus muscle fibers showed that $\sim 50 \%$ of junctions were innervated by more than one motor axon, consistent with anatomical measures of multiple innervation from immunostaining experiments (Fig. 1A,B). At P7$\mathrm{P} 9$, physiological and anatomical measures showed that a large proportion of multiply innervated junctions were innervated by only two axons ( $47 \pm 2$ and $45 \pm 2 \%$, respectively).

The quantal content of each input to dually innervated neuromuscular junctions was measured in $2 \mathrm{~mm} \mathrm{Ca}^{2+} / 13-15 \mathrm{~mm} \mathrm{Mg}^{2+}$ saline. The quantal content of the weaker input was on average $0.4 \pm 0.1$, whereas the quantal content of the stronger input was $0.9 \pm 0.1(n=22)$. The quantal content of the inputs to dually innervated junctions differed from 1-fold to 5.5-fold (mean of $2.7 \pm$ 0.3 -fold; $n=22$ ) (Fig. $1 B$ ), similar to the range of quantal content ratios observed at trapezius neuromuscular junctions at comparable stages (Colman et al., 1997). The quantal content of singly innervated muscle fibers $(0.9 \pm 0.1 ; n=10)$ was similar to the quantal content of the stronger input to dually innervated junctions with the largest disparity in quantal content (more than fourfold difference; $0.9 \pm 0.2 ; n=3$ ). This suggests that, during competition, the weaker input with the lower quantal content is eliminated, the stronger input with the larger quantal content is maintained, and junctions with the largest disparities in quantal content (ratio $>4$ ) (Fig. 1C) are nearest the end of the competitive process (Colman et al., 1997). Given that the quantal content of each input to dually innervated junctions diverges during synaptic competition (Colman et al., 1997), these data suggest that, in the soleus muscle from P7-P9 mice, the changes in synaptic efficacy that accompany the transition from multiple to single innervation have been initiated at most junctions and that different junctions are at different stages of the process.

\section{Differences in paired-pulse facilitation between weak and strong inputs to dually innervated neuromuscular junctions}

Previous work suggested that the divergence in the synaptic strength of competing inputs could be explained by the progressive reduction in the strength of losing inputs. Because synaptic area approximately correlates with the amount of neurotransmitter released (Kuno et al., 1971; Harris and Ribchester, 1979), it was thought that the increasing disparity in the quantal content of each input (Balice-Gordon et al., 1993; Gan and Lichtman, 1998) reflected, for the most part, an increasing disparity in the synaptic territory of each input (Balice-Gordon et al., 1993; Gan and Lichtman, 1998). Thus, a reduction in the number of presynaptic neurotransmitter release sites, as well as a reduction in the quantal effectiveness of remaining release sites attributable to a decrease in postsynaptic AChR density, could explain the progressive reduction in the quantal content of losing inputs. However, quantal content can also be affected by the probability of neurotransmitter release. Although it is difficult to measure release probability directly, an inverse relationship between release probability and the amount of facilitation evident after paired-pulse stimulation $(F)$ is observed at a wide variety of synapses, including adult neuromuscular junctions (Katz and Miledi, 1968; Mallart and Martin, 1968; Creager et al., 1980; Manabe et al., 1993; Dobrunz and Stevens, 1997). If the observed disparity in the quantal content of competing inputs were attributable only to differences in the number of release sites of strong compared with weak inputs, there would be no difference in release probability and no difference in $F$ between the two inputs. On the other hand, if a reduction in neurotransmitter release probability contributed to a reduction in quantal content, $F$ would be greater for weak compared with strong inputs. Thus, $F$ and quantal content were measured for each input 

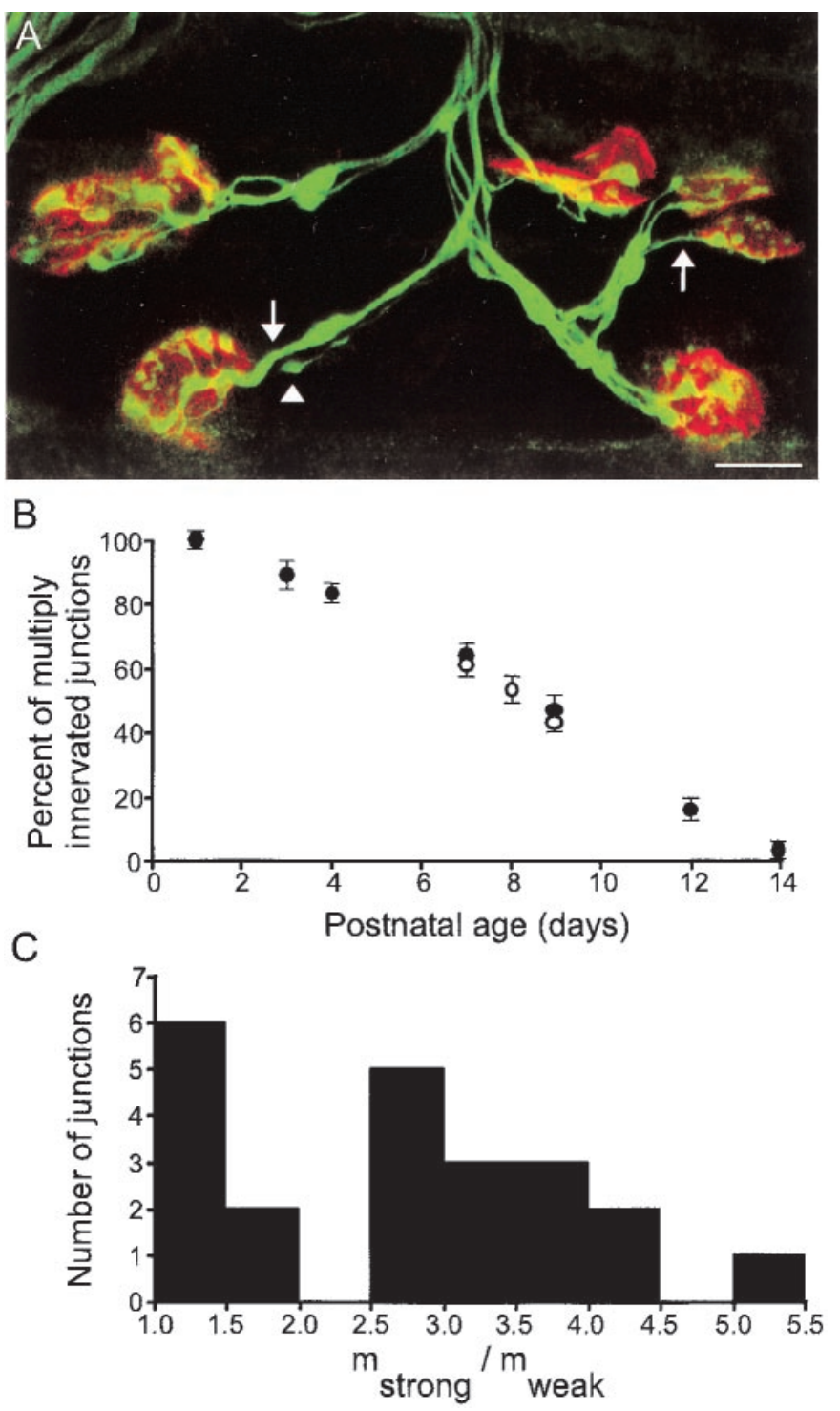

Figure 1. Characterization of synapse elimination in the neonatal mouse soleus muscle. $A$, Immunostaining of motor axons and nerve terminals (green) and AChR clusters (red) at neuromuscular junctions from P7 mouse soleus muscle. At this age, most junctions are innervated by two or more axons. In this field, there are four examples (unlabeled). The terminals of each axon are extensively intermingled over AChR clusters in the postsynaptic muscle fiber membrane. Competition results in the elimination of all but one axon, resulting in the mature pattern of single innervation of each junction. In this field, there are two singly innervated junctions (arrows). Near the single axon innervating the AChR cluster at the bottom left, there is an enlarged bulb-like ending attached to an atrophied axonal branch (arrowhead). These are remnants of the losing axon that withdraws from the junction and are resorbed back into a parent axon in the intramuscular nerve (cf. Balice-Gordon et al., 1993). B, Anatomical (filled circles) and physiological (open circles) measures show that the transition from multiple to single innervation occurs between P0 and P14. Immunostaining showed that, at $\mathrm{P} 1$, all soleus neuromuscular junctions were multiply innervated $(100 \pm 1 \%)$, by P7, more than half were multiply innervated $(64 \pm 2 \%)$, and few junctions remain multiply innervated by P14 $(3 \pm 1 \%)$. Intracellular recording showed that the percentage of junctions multiply innervated at $\mathrm{P} 7, \mathrm{P} 8$, and $\mathrm{P} 9$ was $61 \pm 3,53 \pm 2$, and $43 \pm 2 \%$, respectively. $C$, In junctions from P7-P9 muscles $(n=22)$, the quantal content of each input to dually innervated neuromuscular junctions was determined by the method of failures. The ratio of quantal content for the strong input/weak input varied between 1 and 5.5, with most junctions having a ratio between 2.5 and 4.5 .

to dually innervated neuromuscular junctions, and $F$ was used to estimate the relative probability of neurotransmitter release from each input.

Intracellular recordings, made in $2 \mathrm{mM} \mathrm{Ca}^{2+} / 13-15 \mathrm{mM} \mathrm{Mg}^{2+}$ to prevent contractions, during paired-pulse stimulation at $10 \mathrm{msec}$ i.p.i., showed that $F$ was significantly greater for the weaker compared with the stronger input. A representative example from a dually innervated P8 neuromuscular junction is shown in Figure 2. Input 1 had a smaller epp amplitude $(0.23 \mathrm{mV})($ Fig. $2 A)$, a lower quantal content $(m=0.5)$ (Fig. $2 B)$, and a higher $F$ at $10 \mathrm{msec}$ i.p.i. $(F=1.4)$ (Fig. $2 C)$ compared with input 2 (epp amplitude $=0.37$ $\mathrm{mV} ; m=1.4 ; F=1.0)$. As expected, no facilitation of either input was observed at $1 \mathrm{sec}$ i.p.i. (Fig. $2 D$ ).

The observation that $F$ was significantly greater for the weaker input compared with the stronger input at $10 \mathrm{msec}$ but not at $1 \mathrm{sec}$ i.p.i. held for 17 of 22 junctions examined in $2 \mathrm{mM} \mathrm{Ca}^{2+} / 13-15 \mathrm{~mm}$ $\mathrm{Mg}^{2+}$ (Fig. $3 A$ ). $F_{\text {weak }}$ was significantly greater than $F_{\text {strong }}$ (Fig. $3 B)$ when examined at $10 \mathrm{msec}$ i.p.i. $\left(F_{\text {weak }}=1.7 \pm 0.1 ; F_{\text {strong }}=\right.$ $1.3 \pm 0.1 ; n=22 ; p<0.001$, Student's $t$ test) but not at 1 sec i.p.i. $\left(F_{\text {weak }}=1.0 \pm 0.1 ; F_{\text {strong }}=1.0 \pm 0.1 ; n=22 ; p>0.1\right.$, Student's $t$ test).

Facilitation was also significantly greater for weaker compared with stronger inputs to the same muscle fiber when measurements were made in $4 \mathrm{mM} \mathrm{Ca}^{2+} / 1 \mathrm{mM} \mathrm{Mg}^{2+}$ in the presence of $7-10 \mu \mathrm{M}$ curare (Sigma). $F_{\text {weak }}$ was significantly greater than $F_{\text {strong }}$ when examined at 10 msec i.p.i. $\left(F_{\text {weak }}=1.3 \pm 0.07 ; F_{\text {strong }}=1.0 \pm 0.03\right.$; $n=9 ; p<0.003$, Student's $t$ test $)$ but not at $1 \mathrm{sec}$ i.p.i. $\left(F_{\text {weak }}=\right.$ $0.88 \pm 0.05 ; F_{\text {strong }}=0.80 \pm 0.04 ; n=9 ; p>0.1$, Student's $t$ test $)$. Depression at $1 \mathrm{sec}$ was observed under these conditions for eight of nine cells. In this series of experiments, facilitation was also examined at 20, 50, and $100 \mathrm{msec}$ i.p.i. $F_{\text {weak }}$ and $F_{\text {strong }}$ were significantly different at $20 \mathrm{msec}\left(F_{\text {weak }}=1.1 \pm 0.06 ; F_{\text {strong }}=\right.$ $0.93 \pm 0.05 ; n=9 ; p<0.005$, Student's $t$ test), but no facilitation was observed at 50 and $100 \mathrm{msec}$, and $F$ was similar for weak and strong inputs at 50 and $100 \mathrm{msec}$ (data not shown). Whereas $F_{\text {weak }}$ and $F_{\text {strong }}$ were different at 10 and $20 \mathrm{msec}$, the time course of facilitation across i.p.i was similar between weak and strong inputs (data not shown). Thus, the difference in facilitation between weak and strong inputs to the same junction is also apparent in more physiological concentrations of $\mathrm{Ca}^{2+}$ and $\mathrm{Mg}^{2+}$, albeit in the presence of curare to prevent muscle contractions.

For most neuromuscular junctions examined, $F$ and quantal content were inversely related for weak and strong inputs examined at $10 \mathrm{msec}$ i.p.i. (Fig. 3C) but not at $1 \mathrm{sec}$ i.p.i. (Fig. 3D). $F$ was greater for the weaker input regardless of the absolute value of quantal content for either input (Fig. $3 C$ ). On average, $F_{\text {weak }}$ was significantly greater than $F_{\text {strong }}$ at $10 \mathrm{msec}$ i.p.i. but not at $1 \mathrm{sec}$ i.p.i. (Fig. $3 B, E, F$ ). The relationship between $F$ and quantal content was different for each pair of inputs that coinnervated the same neuromuscular junction, consistent with each pair being at a different stage in the competitive process. Together, these data suggest that the disparity in quantal content between competing inputs is attributable, at least in part, to a disparity in the probability of neurotransmitter release.

\section{Relationship between paired-pulse facilitation and quantal content for weak compared with strong inputs to dually innervated neuromuscular junctions}

Given the inverse relationship between $F$ and the probability of neurotransmitter release, one interpretation of this result is that strong inputs have a higher probability of release than weak inputs at dually innervated neonatal junctions. This interpretation rests on the assumption that developing motor nerve terminals also have an inverse relationship between $F$ and release probability, as has been demonstrated previously for many other synapses (Creager et al., 1980; Manabe et al., 1993; Dobrunz and Stevens, 1997; Dittman et al., 2000), including adult neuromuscular junctions (Katz and Miledi, 1968; Mallart and Martin, 1968; Rahamimoff, 1968). In these cases, when extracellular $\mathrm{Ca}^{2+}$ is low, release probability is low and $F$ values are large $(>1)$; when extracellular $\mathrm{Ca}^{2+}$ is high, release probability is high and $F$ values are small $(<1)$.

To determine whether $F$ and release probability were inversely related at developing motor nerve terminals, in some fibers, intracellular recordings were maintained while the extracellular $\mathrm{Ca}^{2+}$ 
A

Figure 2. Paired-pulse facilitation differs between strong and weak inputs to dually innervated neuromuscular junctions. Representative characterization of a dually innervated neuromuscular junction from a P8 soleus muscle in $2 \mathrm{mM} \mathrm{Ca}^{2+} / 13-15 \mathrm{~mm}$ $\mathrm{Mg}^{2+}$ Ringer's solution. $A$, Sample traces of epp (average of $\sim 1000$ consecutive traces). Amplitude: input 1 (weak), $0.23 \mathrm{mV}$; input 2 (strong), $0.37 \mathrm{mV}$. $B$, epp amplitude histogram, including failures. Quantal content: input $1,0.5$; input $2,1.4$. $C$, Responses to paired-pulse stimulation at $10 \mathrm{msec}$ i.p.i. Facilitation ratio: input 1, 1.4; input 2, 1.0. $D$, Responses to paired-pulse stimulation at $1 \mathrm{sec}$ i.p.i. Facilitation ratio: input 1, 1.0; input 2, 0.9. This depression was not consistently observed. Calibration: $A, C, D, 0.1$ $\mathrm{mV}, 5.0 \mathrm{msec}$. Thus, in this case, input $1 \mathrm{had}$ a smaller epp amplitude, a lower quantal content, and a higher $F$ at 10 msec i.p.i. compared with input 2.
Input 1 (weak)

B
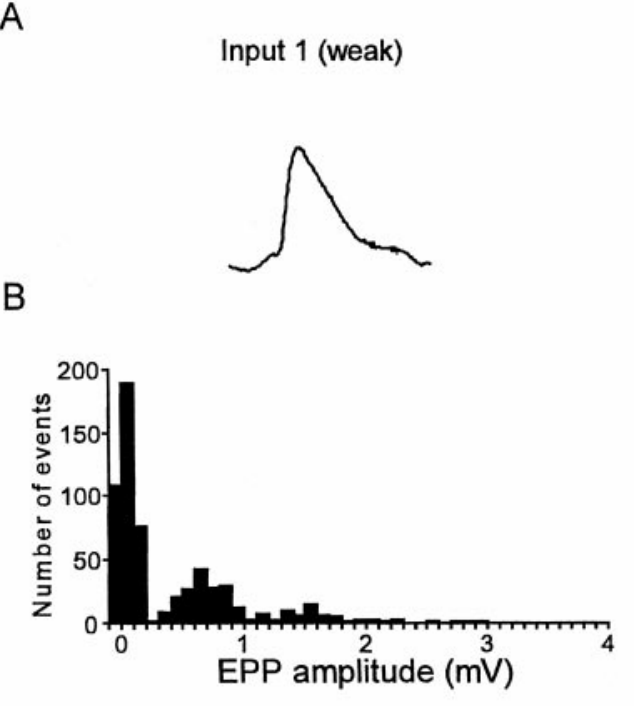

C

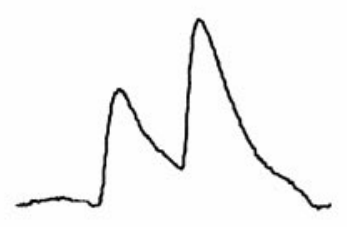

D

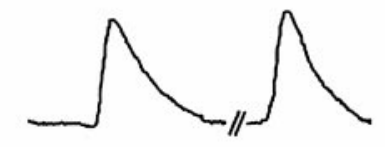

Input 2 (strong)
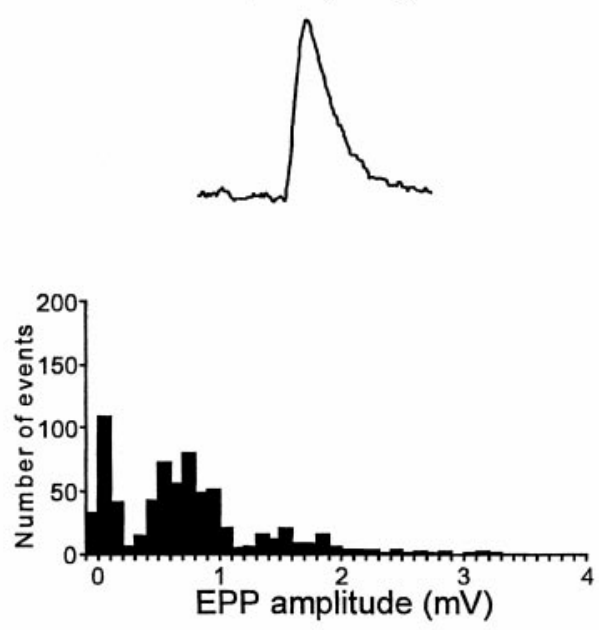

concentration was changed from $1 \mathrm{mM} \mathrm{Ca}^{2+} / 8-10 \mathrm{mM} \mathrm{Mg}^{2+}$ to 4 $\mathrm{mM} \mathrm{Ca}^{2+} / 24-27 \mathrm{~mm} \mathrm{Mg}^{2+}$ (Fig. 4). Paired-pulse facilitation was examined at $10 \mathrm{msec}$ i.p.i. for weak and strong inputs to dually innervated neonatal fibers, and single inputs to neonatal and adult fibers under conditions of low $\left(1 \mathrm{mM} \mathrm{Ca}^{2+}\right)$ and high $\left(4 \mathrm{~mm} \mathrm{Ca}^{2+}\right)$ release probability. In each case, an inverse relationship between $F$ and quantal content was observed at $10 \mathrm{msec}$ i.p.i. (Fig. $4 A-D$ ) but not at $1 \mathrm{sec}$ i.p.i. (data not shown). Thus, each individual input had an inverse relationship between $F$ and extracellular $\mathrm{Ca}^{2+}$, despite differences in quantal content, developmental history, and degree of maturation. This was also true for populations of weak and strong inputs to dually innervated neonatal fibers, and single inputs to neonatal and adult fibers under conditions of low $\left(1 \mathrm{mM} \mathrm{Ca}^{2+}\right)$, normal $\left(2 \mathrm{mM} \mathrm{Ca}^{2+}\right)$, and high $\left(4 \mathrm{mM} \mathrm{Ca}^{2+}\right)$ release probability (Fig. 5A-D).

We next asked why weak inputs become weak, assuming that an initial state exists when all inputs to a muscle fiber are structurally and functionally similar (Creager et al., 1980; Manabe et al., 1993; Dobrunz and Stevens, 1997; Dittman et al., 2000). In this initial state, the relationship between $F$ and $m$ would be similar for all inputs to a muscle fiber. We modeled several possibilities by fitting curves to values of $F$ and $m$ measured in 1-4 mM extracellular $\mathrm{Ca}^{2+}$, for weak and strong inputs to dually innervated neonatal fibers, and single inputs to neonatal and adult fibers (Fig. 5).

The first possibility, consistent with previous work (Creager et al., 1980; Manabe et al., 1993; Dobrunz and Stevens, 1997; Dittman et al., 2000), is that the higher $F$ observed in weak inputs is attributable primarily to changes in the number of neurotransmitter release sites $(n)$. As $n$ is reduced, the relationship between $F$ and $m$ for weak inputs would shift to the left, because only $m$ would be affected (Fig. $5 F 1$ ). The second possibility is that the higher $F$ of weak inputs is attributable primarily to a reduction in $p$. If this were the case, the relationship between $F$ and $m$ for weak inputs would be the same as that for strong inputs but shifted toward higher values of $F$ (Fig. 5F2). The third possibility is that the higher $F$ of weak inputs is attributable to a reduction in both $n$ and $p$. If this were the case, the overall relationship between $F$ and $m$ for weak inputs would be similar to that for a reduction in $n$ only but with weak inputs shifted toward higher $F$ values compared with strong inputs (Fig. 5F3).

However, the data did not fit any of these three possibilities. The experimentally determined relationship between $F$ and $m$ for weak inputs differed from that for strong inputs in two respects (Fig. $5 E$ ). First, it was shifted upward, toward higher asymptotic values of $F$ across all values of $m$. This is not consistent with weak inputs being weak by virtue of decreased $n$ (first possibility above) or a combination of decreased $n$ with decreased $p$ (third possibility above), which would instead have shifted values to the left of those for strong inputs. This upward shift suggests that there is a change in the process of facilitation itself (Fig. 5F4). As inputs become weak, there may be changes in the modulation of neurotransmitter release, or in release machinery itself, that affect facilitation.

Second, values appeared to be shifted upward along the curve, toward lower values of $m$ and higher values of $F$. This suggests that the higher $F$ of weak inputs is attributable not only to a change in the process of facilitation itself but also to a reduction in $p$ (second possibility above). To test this possibility, we calculated the $F$ value for weak and strong inputs in the same range of $m$, from 0 to 0.5 , measured in junctions in $1 \mathrm{mM} \mathrm{Ca}^{2+}$. Not only were more points from weak inputs in this range than from strong inputs, but the average $F$ value was $2.4 \pm 0.2$ for weak inputs $(n=20)$, significantly greater than the value for strong inputs $(1.6 \pm 0.2 ; n=7$; Student's 
A

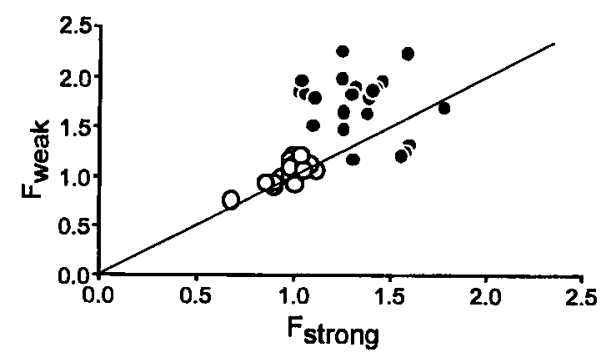

C

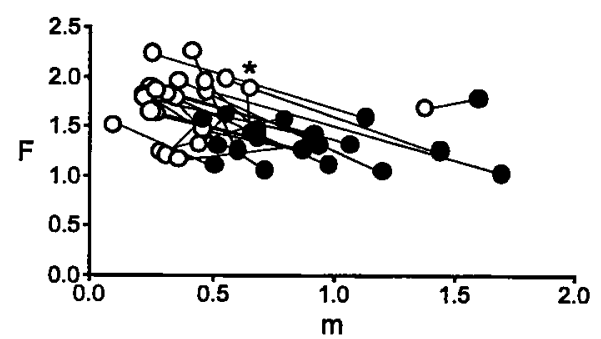

E

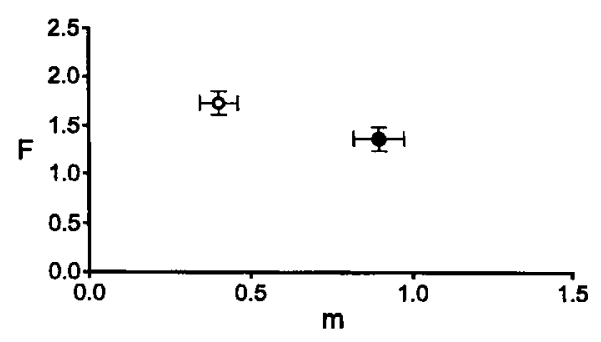

B

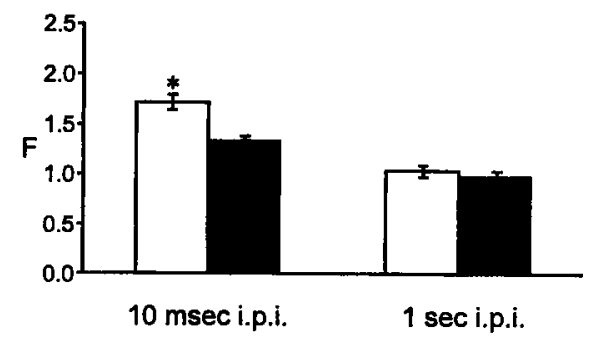

D

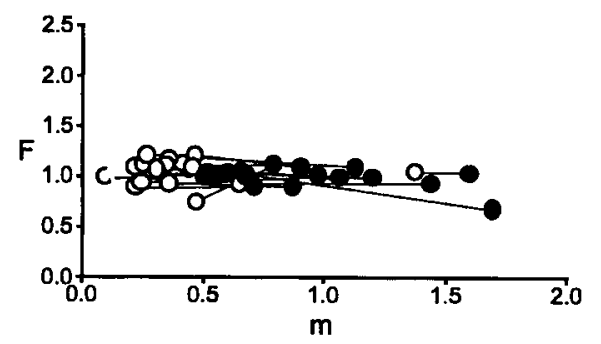

F

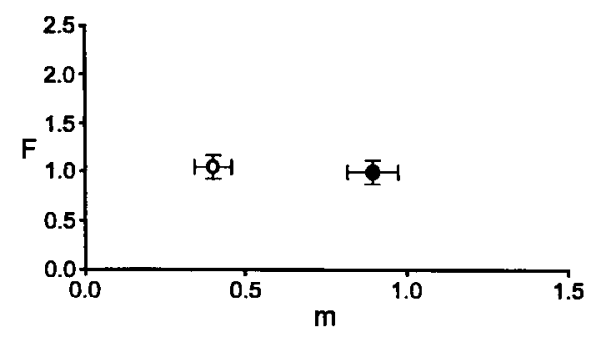

Figure 3. Paired-pulse facilitation is greater for the weak input than the strong input at dually innervated neonatal neuromuscular junctions. $A, F$ at $10 \mathrm{msec}$ i.p.i. (filled circles) and 1 sec i.p.i. (open circles) for weak (smaller quantal content) plotted against $F$ for strong (higher quantal content) inputs to dually innervated neuromuscular junctions examined in $2 \mathrm{mM} \mathrm{Ca}^{2+} / 13-15 \mathrm{~mm}$ $\operatorname{Mg}^{2+}(n=22$ junctions $)$. At $10 \mathrm{msec}$ i.p.i., in 17 of 22 junctions, $F_{\text {weak }}$ was larger than $F_{\text {strong }}$, as evidenced by most points clustering above the thin line that indicates a slope of 1 . At $1 \mathrm{sec}$ i.p.i., $F_{\text {weak }}$ was similar to $F_{\text {strong. }} B$, On average, $F_{\text {weak }}$ (open bars) was significantly greater than $F_{\text {strong }}$ ( filled bars) at $10 \mathrm{msec}$ i.p.i. $(p<0.001$, Student's $t$ test $)$ but not $1 \mathrm{sec}$ i.p.i. ( $p>0.09$, Student's $t$ test). $C, F$ was determined at $10 \mathrm{msec}$ i.p.i. and plotted against quantal content $(\mathrm{m})$ for weak (open circles) and strong ( filled circles) inputs to dually innervated junctions. The two inputs that innervated the same junction are connected by a line. For most pairs of inputs, there is an inverse relationship between $F$ and $m$. Asterisk indicates a pair of inputs in which $m$ was approximately equal for both, but $F$ was different. $D$, At 1 sec i.p.i., similar $F$ was observed between weak and strong inputs. $E$, Mean $F$ at 10 msec i.p.i. is plotted against mean $m$ for all weak (open circle) and all strong (filled circle) inputs. The mean quantal content ratio for all strong and weak inputs to dually innervated junctions examined in $2 \mathrm{~mm}$ $\mathrm{Ca}^{2+} / 13-15 \mathrm{mM} \mathrm{Mg}^{2+}$ was $2.7 \pm 0.3$ (see also Fig. $1 B)$, and the mean $m_{\text {strong }}(0.9 \pm$ 0.1 ) was significantly greater than the mean $m_{\text {weak }}(0.4 \pm 0.1 ; p<0.001$, Student's $t$ test). $F$, At 1 sec i.p.i., no significant difference in $F$ was observed between weak and strong inputs to dually innervated junctions (see also $B$ ). $t$ test, $p<0.005)$. An additional test was performed to determine whether points from weak inputs are shifted along the curve toward lower values of $m$ and higher values of $F$. The ratio of $F / m$ was determined for each value. Inputs with large $m$ and small $F$ would have a small ratio, whereas those with small $m$ and large $F$ would have a large ratio. The ratio for strong inputs was $2.1 \pm 0.3(n=$ 72). Before calculating the ratio for weak inputs, we shifted their $F$ value downward by the average difference in $F$, determined from the curve fits of the data from all muscle fibers (Fig. 5E). After this shift, the ratio for weak inputs was $6.1 \pm 1.3$, significantly larger than for strong inputs $(p<0.001$; Mann-Whitney test). Thus, weak inputs had higher $F$ values than strong inputs across all values of $m$, consistent with a change in the process of facilitation, and were also shifted to the left, upwards along the curve, consistent with a decreased release probability in weak inputs (Fig. 5F4).

The relationship between $F$ and $m$ for single inputs to neonatal junctions was observed to be shifted to the right of that for strong inputs to dually innervated junctions (although this was not significant; see legend to Fig. 5). The relationship for adult junctions was shifted to the right of that for strong inputs to dually innervated junctions and that for single inputs to neonatal junctions (Fig. 5E). This is consistent with a gradual increase in $n$, as well as with an increase in $n$ and $p$, as inputs mature.

\section{Progressive disparity in release probability among competitors}

Previous work has shown that the quantal content ratio ( $\left.m_{\text {strong }}\right)$ $m_{\text {weak }}$ ) of competing inputs becomes progressively larger during postnatal life, as the transition from multiple to single innervation progresses (Colman and Lichtman, 1997). Because it was not possible to make stable recordings over long times from younger muscles, quantal content ratio was used as a proxy for developmen- tal time and to thus probe different stages in the progress of synaptic competition. We observed that $F$ for weak inputs $\left(F_{\text {weak }}\right.$; open circles) becomes progressively greater as quantal content ratio increases, whereas $F_{\text {strong }}$ (filled circles) decreases (Fig. 6). The disparity between $F_{\text {weak }}$ and $F_{\text {strong }}$ becomes apparent at a quantal content ratio near 2 , which has been observed at junctions relatively early in the transition from multiple to single innervation (Colman and Lichtman, 1997). These data suggest that a change in release probability between competitors is likely to be an early event in the process of synaptic competition.

\section{DISCUSSION}

Intracellular recordings from dually innervated neonatal mouse soleus muscle fibers were used to characterize changes in synaptic function that occur during competition. Quantal content and paired-pulse facilitation, a measure of synaptic function that is inversely related to neurotransmitter release probability, were compared between weak and strong inputs to the same neuromuscular junction. Paired-pulse facilitation was greater for the weaker input compared with the stronger input, regardless of their absolute quantal content. This suggests that weaker inputs have a lower probability of neurotransmitter release than stronger inputs to the same junction. This difference in facilitation between weak and strong inputs to the same junction was apparent across a range of $\mathrm{Ca}^{2+}$ and $\mathrm{Mg}^{2+}$ concentrations and also when $m$ was reduced by adding curare to the recording solution. This suggests that the differences in facilitation and quantal content may be functionally significant in vivo. Together, our results suggest that differences in presynaptic neurotransmitter release contribute to the increasing disparity in quantal content that is a hallmark of the competitive process. 
Figure 4. Relationship among pairedpulse facilitation and quantal content at individual junctions as extracellular $\mathrm{Ca}^{2+}$ was varied. $A-D$, Continuous recordings were made from some individual neuromuscular junctions as extracellular $\mathrm{Ca}^{2+}$ was varied from $1 \mathrm{~mm}$ (left circle of each pair joined by a line) to $4 \mathrm{~mm}$ (right circle of each pair), and the extent of pairedpulse facilitation at $10 \mathrm{msec}$ i.p.i. and quantal content were determined for weak $(A)$ and strong $(B)$ inputs to dually innervated P7-P9 junctions $(n=16)$, singly innervated P7-P9 $(C ; n=28)$, and adult junctions $(D ; n=12)$. In each case, an inverse relationship between $F$ and $m$ was observed. $E$, Summary of $F$ and $m$ for weak (open circles) and strong (filled circles) inputs to dually innervated junctions and single inputs to neonatal (open squares) and adult (filled squares) junctions. Left symbol of each pair represents mean \pm SEM measured in low $(1 \mathrm{mM})$ calcium, and right symbol represents mean \pm SEM measured in high $(4 \mathrm{mM})$ calcium. For weak inputs (open circles), in low $\mathrm{Ca}^{2+}, F_{\text {weak }}=2.9 \pm 0.2, m_{\text {weak }}=$ $0.3 \pm 0.1$; in high $\mathrm{Ca}^{2+}, F_{\text {weak }}=1.6 \pm$ $0.2, m_{\text {weak }}=0.7 \pm 0.1$. For strong inputs (filled circles), in low $\mathrm{Ca}^{2+}, F_{\text {in }}=$ $1.4 \pm 0.1, m_{\text {strong }}=0.8 \pm 0.1$; in high $\mathrm{Ca}^{2+}, F_{\text {strong }} \stackrel{=}{=} 1.0 \pm 0.1, m_{\text {strong }}=$ $1.5 \pm 0.1$. For single inputs to neonatal junctions (open squares), in low $\mathrm{Ca}^{2+}$, $F_{\text {single }}=1.9 \pm 0.2, m_{\text {single }}=0.6 \pm 0.1$; in high $\mathrm{Ca}^{2+}, F_{\text {single }}=1.0^{\text {single }} \pm 0.1, m_{\text {single }}=$ $1.3 \pm 0.1$. For single inputs to adult junctions ( filled squares), in low $\mathrm{Ca}^{2+}$, $F_{\text {adult }}=1.6 \pm 0.1, m_{\text {adult }}=0.6 \pm 0.1$; in high $\mathrm{Ca}^{2+}, \bar{F}_{\text {adult }}=1.1 \pm 0.1, m_{\text {adult }}=$ $1.2 \pm 0.1$
A

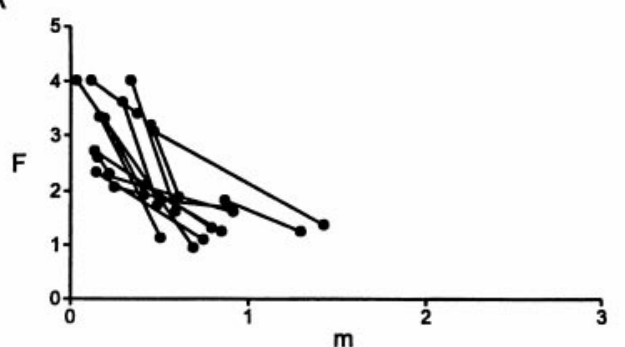

C

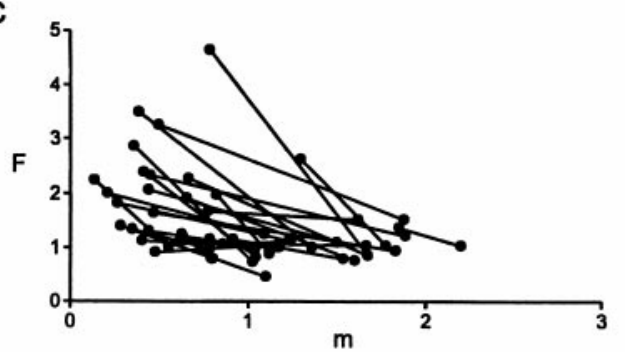

E

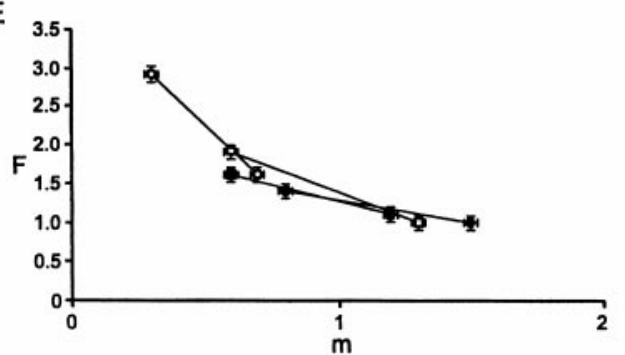

B

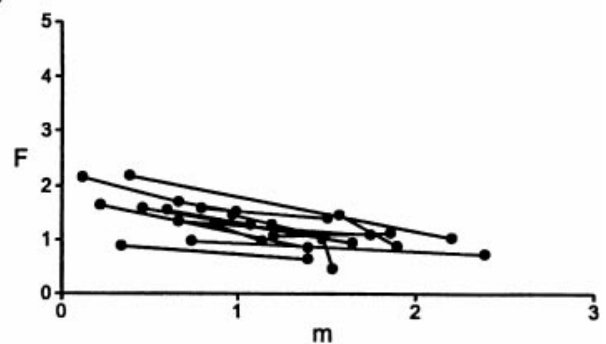

D

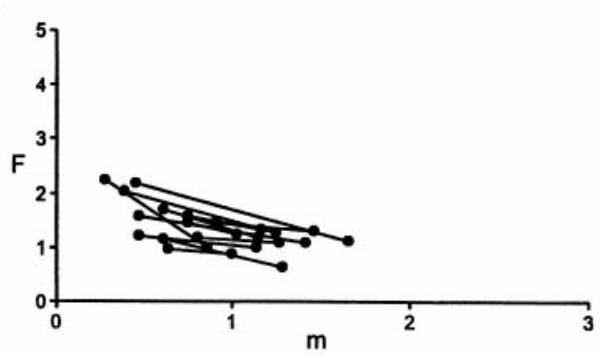

\section{How do inputs become weak during synaptic competition?}

Our results show that weak inputs had higher paired-pulse facilitation than strong inputs to dually innervated junctions, across similar ranges of quantal content. This difference was observed at 10 msec i.p.i. but not at $1 \mathrm{sec}$, in high $\mathrm{Mg}^{2+}$ Ringer's solution, and at 10 and $20 \mathrm{msec}$ but not at $1 \mathrm{sec}$, in $4 \mathrm{~mm} \mathrm{Ca}^{2+} / 1$ $\mathrm{mm} \mathrm{Mg}^{2+}$ with curare. The difference in $F$ at short i.p.i. raises the issue of whether these intervals are physiologically relevant, given the firing rates of soleus motor neurons in vivo. We have measured the firing patterns and rates of single motor units from neonatal mouse soleus muscle (Personius and Balice-Gordon, 1999; K. Personius and R. Balice-Gordon, unpublished observations). This work shows that the firing patterns of soleus motor units are quite phasic at P6-P8 and that, within bursts, interevent intervals range from 10 to $50 \mathrm{msec}$. Tonic firing patterns, similar to those seen in adult rodents, are not apparent until P14-P15 and later. Together, our data suggest that the differences in $F$ and $m$ are functionally significant under physiological conditions and not evident only under artificial conditions.

Based on previous observations of a progressive disparity in the presynaptic terminal area of competitors (Balice-Gordon et al., 1993; Colman et al., 1997) and a concomitant disparity in quantal content (Colman et al., 1997), the simplest explanation for the difference in $F$ is that the $n$ of weak inputs, and thus their $m$, is less than that of strong inputs to the same junction. We modeled the possibility that the difference in $F$ between weak and strong inputs is attributable to a difference in $n$ and thus their $m$, as well as several other possibilities. If the higher $F$ of weak inputs were attributable primarily to a decrease in $n$, then the relationship between $F$ and $m$ for weak inputs would shift to the left of that of strong inputs, because only $m$ would be affected (Fig. 5F1). Our data were not consistent with this possibility (Fig. $5 E$ ).

A second possibility is that the higher $F$ of weak inputs is attributable primarily to a reduction in $p$. If this were the case, the relationship between $F$ and $m$ for weak inputs would be on the same curve as that for strong inputs but shifted along that curve toward higher values of $F$ and lower values of $m$ (Fig. 5F2). This was in fact observed (Fig. 5), suggesting that weak inputs had a lower release probability than strong inputs. In addition, however, there was an upward shift in $F$ across the same values of $m$ for weak and strong inputs. The possibility that weak inputs could increase their facilitation, without reducing release probability, seems unlikely, because weak inputs had a significantly higher $F$ than strong inputs across the same range of $m$, even when considering the upward shift in $F$. Moreover, there was no difference in the time course of facilitation across a range of i.p.i. between weak and strong inputs. Together, then, these data suggest that inputs may become progressively weak not only by a reduction in neurotransmitter release probability but also by a change in the process of facilitation itself. Whereas using paired-pulse facilitation to probe release probability is indirect, a more direct measure might be obtained by differential labeling of competing inputs with FM dyes, followed by optical measurement of destaining rates, for example (cf. Betz and Bewick, 1992). However, the extensive spatial overlap among competing inputs at small, compact neonatal junctions would make interpretation difficult, and this method would preclude a determination of the quantal content of each input, thereby preventing identification of strong and weak inputs.

Surprisingly, an increase in the $n$ of strong inputs to dually innervated junctions does not appear to contribute to the increasing disparity in $m$ between weak and strong inputs. If this were the case, the relationship between $F$ and $m$ for strong inputs would be shifted to the right of the curve for weak inputs. The absence of such a rightward shift suggests that inputs become relatively stronger because other inputs are weakened. Thus, it appears that the weakening of one input, rather than the differential strengthening of competitors, is a major, early contributor to the increasing 
A

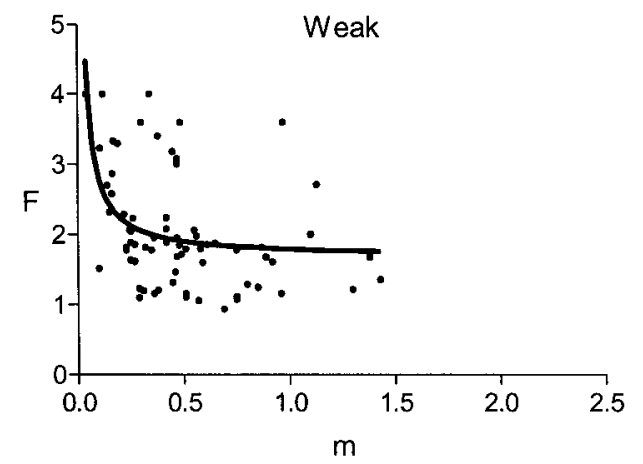

C

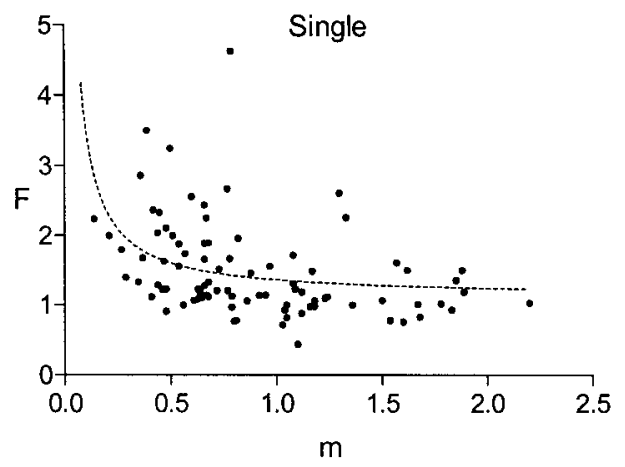

E

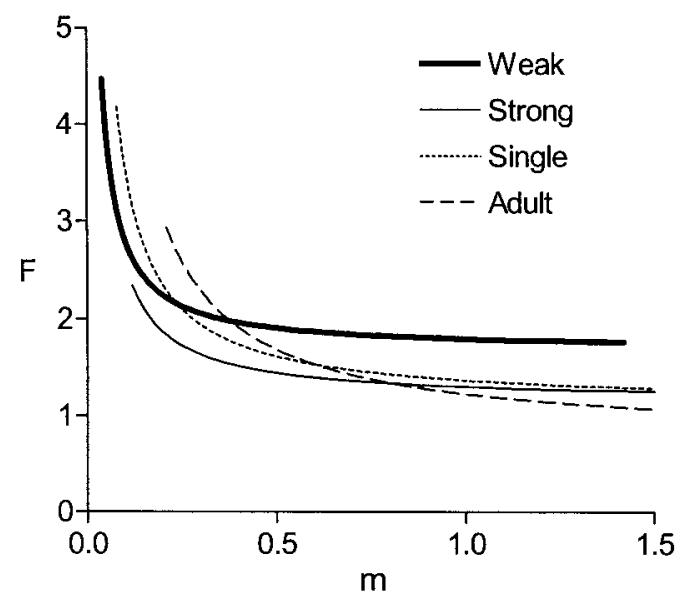

B

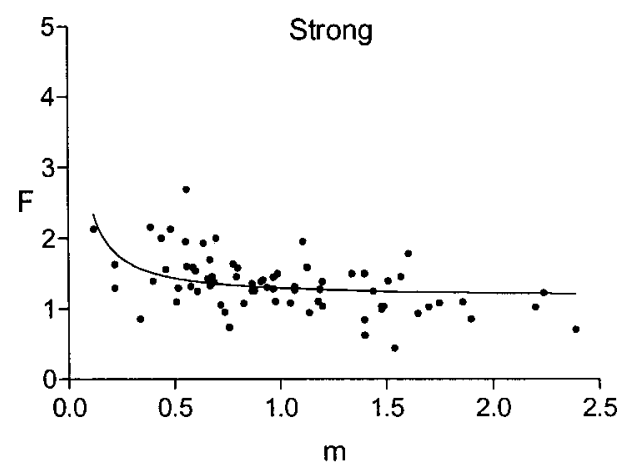

D

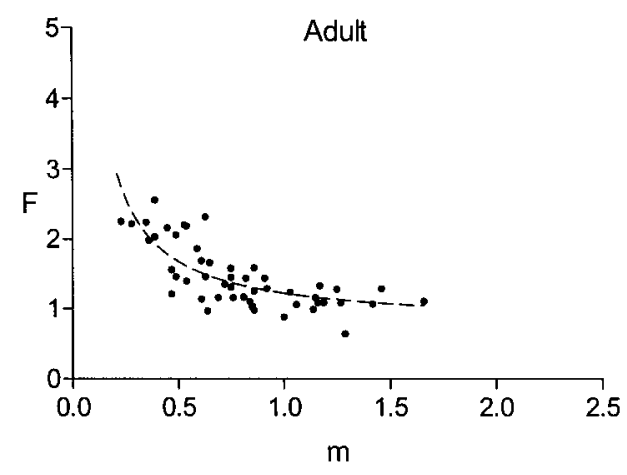

$F_{1}$

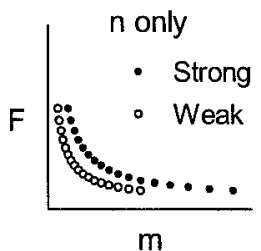

3

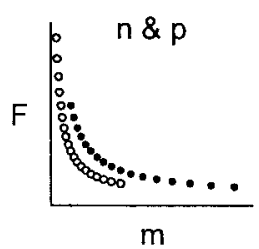

Figure 5. Relationship among pairedpulse facilitation, quantal content, release probability, and number of release sites. $A-D$, Scatter plot of $F$ at $10 \mathrm{msec}$ i.p.i. and $m$ for individual junctions collected in 1,2 , and 4 $\mathrm{mM} \mathrm{Ca}{ }^{2+}$ for weak $(A)$ and strong $(B)$ inputs to dually innervated junctions $(n=72)$ and single inputs to neonatal $(C ; n=89)$ and adult $(D ; n=50)$ junctions. In each case, increasing $\mathrm{Ca}^{2+}$ decreased $F$ and increased $m$ (data not shown), resulting in an inverse relationship. The best-fit curve to each data set was defined by a simple hyperbola, $y=y_{0}+a / x$, shifted along the ordinate. $E$, Comparison of best-fit curves for each data set, made using a nonlinear, least-squares fitting algorithm. Best-fit parameters, $y_{0}$ and $a$, were compared using a one-way ANOVA, followed by Tukey's multiple comparison post hoc test. The shape of curves, affected by the parameter $a$, was similar for weak and strong inputs to dually innervated junctions (weak $a=0.11 \pm 0.03 ;$ strong $a=0.14 \pm$ 0.04; not significantly different, $p>$ $0.05)$. However, the curve for weak inputs was shifted upward, toward higher $F$ values for the same range of $m$ (weak $y_{0}=1.68 \pm 0.12$, strong $\left.y_{0}=1.16 \pm 0.07 ; p<0.01\right)$. The curve for strong inputs was similar to that for singly innervated neonatal junctions $\left(y_{0}=1.12 \pm 0.12 ; a=\right.$ $0.25 \pm 0.07$; not significantly different, $p>0.05)$. However, the curve for single inputs to neonatal junctions was shifted to the right of that for strong inputs, although the shape parameter $a$ was not significantly different. The curve for adult junctions had a similar $y_{0}$ as that for single inputs $\left(y_{0}=0.77 \pm\right.$ 0.1 ; not significantly different, $p>$ $0.05)$, but the shape of the curve was different $(a=0.46 \pm 0.06 ; p<$ 0.05 ) and was shifted to the right, as would be expected if adult inputs had a higher number of release sites, $n$, than neonatal inputs. $F$, The relative contributions of $n$ and $p$ were evaluated by constructing a simple quantitative model of the relationship between $F$ and $m$. We assumed that a reciprocal relationship exists between $F$ and $p$, such that their product is a constant. 1 , If the higher $F$ of weak inputs were attributable primarily to changes in $n$, then when $n$ is reduced twofold, the entire curve would be shifted to

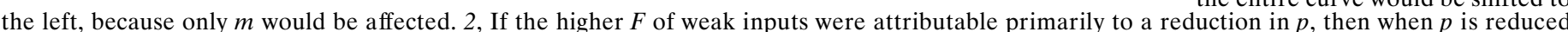

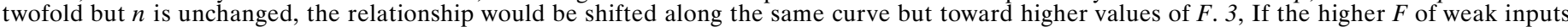

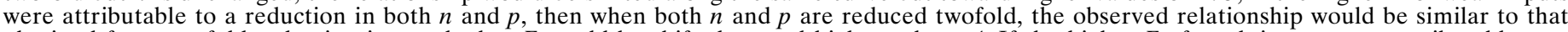

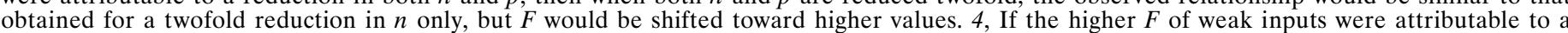

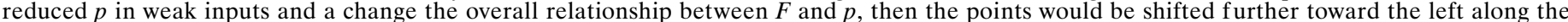

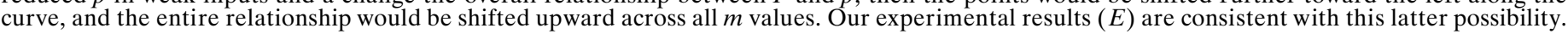

disparity in quantal content that is a consequence of the competitive process (Colman et al., 1997). These observations are consistent with previous work that focused on anatomical changes in the terminal arbors of competing inputs to the same junctions (BaliceGordon et al., 1993; Colman et al., 1997). Losing inputs undergo a frank loss of terminal area, whereas winning inputs do not seem to add new terminal regions. Thus, the loss of the terminals of one input, rather than differential growth, contributes to the increasing disparity in the terminal arbors of competitors.

A shift to the right in the relationship between $F$ and $m$ was detected for single inputs to neonatal and adult junctions (Fig. 5E), as would be expected for a gradual increase in $n$, or $n$ as well as $p$, with maturation. Moreover, because strong inputs become single inputs, the shift to the right in the relationship between $F$ and $m$ of single inputs to neonatal and adult junctions, suggesting an increase in $n$ (Fig. $5 E$ and above), is also consistent with previous anatomical observations. The growth of winning inputs through adulthood occurs by the expansion of existing terminal regions (BaliceGordon et al., 1993; Colman et al., 1997) and presumably the addition of active zones within expanded terminals.

What may underlie the reduction of neurotransmitter release probability as well as alter the facilitation process? Differences 


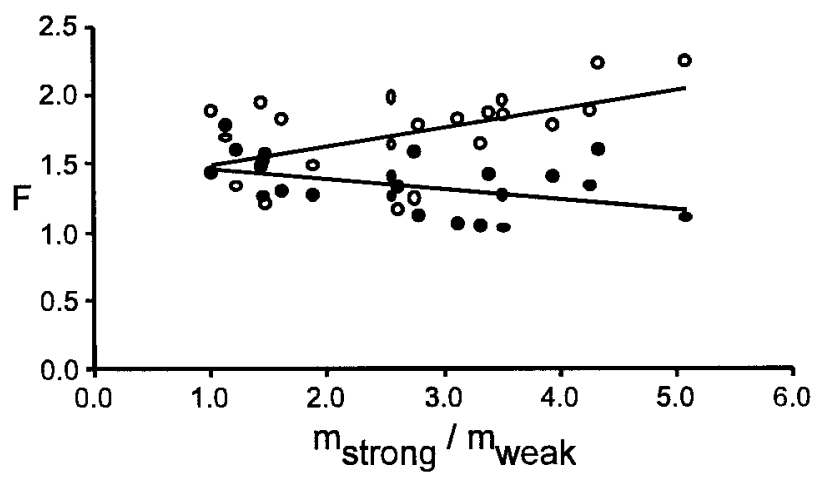

Figure 6. Progressive disparity in $F$ of weak compared with strong inputs compared with progressive disparity in quantal content. Previous work has shown that the quantal content ratio $\left(m_{\text {strong }} / m_{\text {weak }}\right)$ of competing inputs becomes progressively larger during postnatal life, as the transition from multiple to single innervation progresses (Colman and Lichtman, 1997). The $F$ of weak inputs $\left(F_{\text {weak }}\right.$; open circles $)$ becomes progressively greater as quantal content ratio increases, whereas $F_{\text {stron }}$ (filled circles) decreases. Solid lines indicate regression lines for weak (top line) and strong (bottom line) inputs. The two slopes are significantly different $(p<0.05$, Student's $t$ test $)$. The disparity between $F_{\text {weak }}$ and $F_{\text {strong }}$ becomes apparent at a quantal content ratio near 2, representative of junctions relatively early in the process of synaptic competition (Colman and Lichtman, 1997).

in $\mathrm{Ca}^{2+}$ buffering affect facilitation (cf. Hochner et al., 1991; Cuttle et al., 1998; Lee et al., 2000), and these may arise, in part, from differences in the expression of $\mathrm{Ca}^{2+}$ buffering proteins. Moreover, differences in the types and/or distribution of $\mathrm{Ca}^{2+}$ channels in weak and strong inputs may also affect facilitation. Newly formed rat motor nerve terminals have a different repertoire of voltage-sensitive $\mathrm{Ca}^{2+}$ channels than more mature terminals (Betz and Bewick, 1992; Murthy et al., 1997; Costanzo et al., 1999). Sugiura and Ko (1997) suggest that L-type channels on developing, but not adult, nerve terminals may limit the amount of neurotransmitter released. The disparity in neurotransmitter release probability and facilitation that we report here might be related, at least in part, to differences in the expression of L-type calcium channels. Pharmacological manipulations that selectively affect L-type and other $\mathrm{Ca}^{2+}$ channels and differential labeling of inputs (Betz and Bewick, 1992; Murthy et al., 1997; Costanzo et al., 1999) combined with immunohistochemistry for $\mathrm{Ca}^{2+}$ channel types and distribution may allow this possibility to be addressed.

Another possibility for the disparity in release probability and facilitation between competing inputs may be a difference in the maturation of vesicle release machinery, including structural maturation of active zones. Although proteins involved in neurotransmitter release continue to be elucidated, the developmental regulation of release machinery is poorly understood (Rosenmund and Stevens, 1996; Murthy et al., 1997). Recent work has suggested that the probability of neurotransmitter release may be related to the number of docked vesicles, because decreasing this pool decreases release probability (Rosenmund and Stevens, 1996; Murthy et al., 1997). Thus, it is possible that the pool of docked vesicles, or some other aspect of release machinery, is depleted or otherwise compromised in inputs that have a low release probability, a low quantal content, and that ultimately lose neuromuscular synaptic competition.

\section{Cascade of events underlying synaptic competition}

The results presented here raise the question of whether the changes in $F$ and $m$ of weak compared with strong inputs are the cause, or the effect, of competition. Although a detailed molecular and cellular understanding of the mechanisms underlying competition is gradually emerging, our data suggest that a change in neurotransmitter release probability and the facilitation process is an early event in competition and that this change contributes to a progressive disparity in $m$ that is the functional measure of the efficacy of an input. Collectively, the available data on competition at neuromuscular and most other synapses (Katz and Shatz, 1996; Sejnowski, 1999; Lichtman and Colman, 2000) support an activity-dependent positive feedback mechanism in which gradual changes in synaptic strength and synaptic area contribute to the long-term viability of an input. Inactive inputs that release less neurotransmitter than more active competitors may downregulate synaptic release machinery, resulting in the decrease in release probability that we describe here for weak inputs to dually innervated junctions. Postsynaptic AChRs may then become depleted under low probability sites in a stepwise manner, followed by the loss of overlying presynaptic terminal regions. AChR loss from each individual site is rapid, occurring over several hours (Balice-Gordon and Lichtman, 1993). In some cases, the presence of low-density AChR regions can be detected physiologically as a population of epps with smaller quantal amplitude. However, these sites are relatively short-lived, making them hard to detect structurally and functionally. Repeated cycles of functional weakening and structural loss likely continue until weakened inputs permanently withdraw from the synapse.

Active inputs, on the other hand, emerge as winners in the competitive process, by maintaining a high quantal content, in part by maintaining a higher release probability than their competitors. High release probability may, in turn, prevent the depletion of postsynaptic receptors, preserving synaptic area and strength. After single innervation is established, quantal content increases further until adulthood, probably by the gradual addition of release sites. A similar modulation of presynaptic release mechanisms, coupled to changes in postsynaptic neurotransmitter receptor density, may account for structural and functional plasticity commonly observed at neuron-neuron synapses in the developing and mature brain (Lissen et al., 1999; Quinlan et al., 1999; Shi et al., 1999).

\section{REFERENCES}

Balice-Gordon RJ, Lichtman JW (1993) In vivo observations of pre- and postsynaptic changes during the transition from multiple to single innervation at developing neuromuscular junctions. J Neurosci 13:834-855.

Balice-Gordon RJ, Chua CK, Nelson CC, Lichtman JW (1993) Gradual loss of synaptic cartels precedes axon withdrawal at developing neuromuscular junctions. Neuron 11:801-815.

Betz WJ, Bewick GS (1992) Optical analysis of synaptic vesicle recycling at the frog neuromuscular junction. Science 255:200-203.

Colman H, Nabekura J, Lichtman JW (1997) Alterations in synaptic strength preceding axon withdrawal. Science 275:356-361.

Costanzo EM, Barry JA, Ribchester RR (1999) Co-regulation of synaptic efficacy at stable polyneuronally innervated neuromuscular junctions in reinnervated rat muscle. J Physiol (Lond) 521:365-374.

Creager R, Dunwiddie T, Lynch G (1980) Paired-pulse and frequency facilitation in the CA1 region of the in vitro rat hippocampus. J Physiol (Lond) 299:409-424.

Cuttle MF, Tsujimoto T, Forsythe ID, Takahashi T (1998) Facilitation of the presynaptic $\mathrm{Ca}^{++}$current at an auditory synapse in rat brainstem. J Physiol (Lond) 512:721-729.

Del Castillo J, Katz B (1954) Quantal components of the end-plate potential. J Physiol (Lond) 124:560-573.

Dittman JS, Kreitzer AC, Regehr WG (2000) Interplay between facilitation, depression, and residual calcium at three presynaptic terminals. J Neurosci 20:1374-1385.

Dobrunz LE, Stevens CF (1997) Heterogeneity of release probability, facilitation, and depletion at central synapses. Neuron 18:995-1008.

Gan WB, Lichtman JW (1998) Synaptic segregation at the developing neuromuscular junction. Science 282:1508-1511.

Gonzalez M, Ruggiero FP, Chang Q, Shi YJ, Rich MM, Kraner S, BaliceGordon RJ (1999) Disruption of TrkB-mediated signaling induces disassembly of postsynaptic receptor clusters at neuromuscular junctions. Neuron 24:567-583.

Harris JB, Ribchester RR (1979) The relationship between end-plate size and transmitter release in normal and dystrophic muscles of the mouse. J Physiol (Lond) 296:245-265.

Hochner B, Parnas H, Parnas I (1991) Effects of intra-axonal injection of $\mathrm{Ca}^{++}$buffers on evoked release and on facilitation at crayfish neuromuscular junctions. Neurosci Lett 125:215-218.

Katz B, Miledi R (1968) The role of calcium in neuromuscular facilitation. J Physiol (Lond) 195:481-492.

Katz LC, Shatz CJ (1996) Synaptic activity and the construction of cortical circuits. Science 274:1133-1138. 
Kopp DM, Balice-Gordon RJ (1999) Changes in the probability of neurotransmitter release during synaptic competition at developing neuromuscular junctions. Soc Neurosci Abstr 25:1556.

Kuno M, Turkanis SA, Weakly J (1971) Correlation between nerve terminal size and transmitter release at the neuromuscular junction of the frog. J Physiol (Lond) 213:545-556.

Lee SH, Rosenmund C, Schwaller B, Neher E (2000) Differences in $\mathrm{Ca}^{++}$ buffering properties between excitatory and inhibitory hippocampal neurons from the rat. J Physiol (Lond) 525:405-418.

Lichtman JW, Colman H (2000) Synapse elimination and indelible memory. Neuron 25:269-278.

Lissen DV, Carroll RC, Nicoll RA, Malenka RC, von Zastrow M (1999) Rapid, activation-induced redistribution of ionotropic glutamate receptors in cultured hippocampal neurons. J Neurosci 19:1263-1272.

Mallart A, Martin AR (1968) The relation between quantum content and facilitation at the neuromuscular junction of the frog. J Physiol (Lond) 196:593-604

Manabe T, Wyllie DJA, Perkel DJ, Nicoll RA (1993) Modulation of synaptic transmission and long-term potentiation: effects on paired pulse facilitation and EPSC variance in the CA1 region of the hippocampus. J Neurophysiol 70:1451-1459.

Murthy VN, Sejnowski TJ, Stevens CF (1997) Heterogeneous release properties of visualized individual hippocampal synapses. Neuron 18:599-612.
Personius KE, Balice-Gordon RJ (1999) Motor unit activity during synaptic competition at developing neuromuscular junctions. Soc Neurosci Abstr 25:1557.

Quinlan EM, Philpot BD, Huganir RL, Bear MF (1999) Rapid, experience-dependent expression of synaptic NMDA receptors in visual cortex in vivo. Nat Neurosci 2:352-357.

Rahamimoff R (1968) A dual effect of calcium ions on neuromuscular facilitation. J Physiol (Lond) 195:471-480.

Rees D (1978) A non-phosphate-buffered physiological saline for in vitro electrophysiological studies on the mammalian neuromuscular junction. J Physiol (Lond) 278:8P-9P.

Ribchester RR, Mao F, Betz W (1994) Optical measurements of activitydependent membrane recycling in motor nerve terminals of mammalian skeletal muscle. Proc R Soc Lond B Biol Sci 255:61-66.

Rosenmund C, Stevens CF (1996) Definition of the readily releasable pool of vesicles at hippocampal synapses. Neuron 16:1197-1207.

Sejnowski TJ (1999) The book of Hebb. Neuron 24:773-776.

Shi SH, Hayashi Y, Petralia RS, Zaman SH, Wenthold RJ, Svoboda K, Malinow R (1999) Rapid spine delivery and redistribution of AMPA receptors after synaptic NMDA receptor activation. Science 284: $1811-1816$.

Sugiura Y, Ko C-P (1997) Novel modulatory effect of L-type calcium channels at newly formed neuromuscular junctions. J Neurosci 17:11011111. 